This document was prepared in conjunction with work accomplished under Contract No. DE-AC09-96SR18500 with the U.S. Department of Energy.

This work was prepared under an agreement with and funded by the U.S. Government. Neither the U. S. Government or its employees, nor any of its contractors, subcontractors or their employees, makes any express or implied: 1 . warranty or assumes any legal liability for the accuracy, completeness, or for the use or results of such use of any information, product, or process disclosed; or 2 . representation that such use or results of such use would not infringe privately owned rights; or 3 . endorsement or recommendation of any specifically identified commercial product, process, or service. Any views and opinions of authors expressed in this work do not necessarily state or reflect those of the United States Government, or its contractors, or subcontractors. 
Proceedings of the $11^{\text {th }}$ International Conference on Environmental Remediation and Radioactive Waste Management

ICEM2007

September 2-6, 2007, Oud Sint-Jan Hospital Conference Center, Bruges, Belgium

ICEM07 7199

\title{
INNOVATIVE INTEGRATION OF DECOMMISSIONING AND DEACTIVATION PROGRAM WITH SOIL-GROUNDWATER CLEAN UP PROGRAM HAS POSITIVE RESULTS ON BUDGET AND SCHEDULE: A CASE STUDY
}

\author{
Authors: Bruce G. Schappell, P.E. \\ Soil and Groundwater Closure Projects-Area Project Manager, Bechtel Savannah River \\ Company; and \\ Gregory G. Rucker, B.S., M.S, Soil and Groundwater Closure Projects, Senior Advisory Engineer \\ Washington Savannah River Company \\ 730-4B, Room 333 \\ Aiken, South Carolina 29808 \\ bruce.schappell@srs.gov, 803-952-6541 \\ gregory.rucker@srs.gov, 803-952-6683
}

\begin{abstract}
An innovative approach to integrate the activities of a decommissioning and deactivation program (D\&D) with a soilgroundwater clean up program has had significant positive results saving both money and time at the Department of Energy's Savannah River Site. The accomplishments that have been achieved by the combining the two programs have been remarkable including significant cost savings, economies of scale for sampling and document generation, and alignment of common objectives.
\end{abstract}

Because of the coordination of both activities area-wide "end states" can be formulated and be consistent with the customers' cleanup goals and federal regulations. This coordinates and aligns both the environmental clean up and D\&D objectives because each must be addressed simultaneously and comprehensively. In this respect, resources from both organizations can be pooled to take advantage of the strengths of each. The new approach allows more efficient use of lean financial resources and optimizes workforce activities to attain the common objectives while being more cost effective, more protective of the environment, and optimizing the use existing resources.

\section{NOMENCLATURE}

Deactivation and Decommissioning Program (DDP) is designed to decommission, deactivate, or demolish former legacy support and former production facilities used for the production of nuclear materials at the Savannah River Site.

Federal Facility Agreement is a document authored by the US Department of Energy, US Environmental Protection Agency, and South Carolina Department of Health and Environmental Control which enumerates the waste sites and former production facilities which need to be investigated and remediated to protect human health and the environment.

The Soil and Groundwater Closure Program (SGP) is designed to clean up soil and groundwater contaminated with a variety of chemicals and radionuclides as a result of nuclear material production over a 50 year span.

\section{Savannah River Site Background}

The Savannah River Site (SRS) comprises an area approximately $800 \mathrm{~km}^{2}$ and is located in the southeaster United States in South Carolina. The United States 
Department of Energy owns SRS and it is operated by the Washington Savannah River Company which provides management and operating services. Since its creation in 1951, SRS has historically produced nuclear materials including tritium, plutonium, and other special nuclear materials for the national defense program. SRS has provided nuclear material for the space program and for medical, industrial, and research efforts. Chemical and radioactive wastes are byproducts of the nuclear material production processes and these byproducts have found their way into the environmental and contaminated soil and groundwater and production buildings.

SRS is listed on the Environmental Protection Agency National Priority List and is regulated by the Environmental Protection Agency (EPA) and the State of South Carolina Department of Health and Environmental Control (DHEC) under the Comprehensive Environmental Response, Compensation (CERCLA) and Liability Act and the Resource Conservation and Recovery Act (RCRA). The United States Department of Energy, EPA, and DHEC have been involved in an agreement to coordinate clean up activities at SRS since 1989.

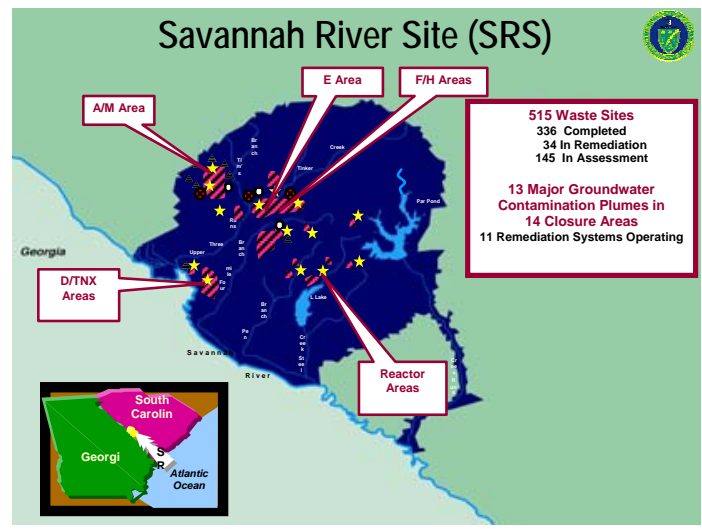

Figure 1. The Savannah River Site

\section{THE OLD PARADIGM}

Historically, SRS used two independent programs to address D\&D and environmental clean up issues at the SRS complex. Both programs were independently funded, reported to different managers, and worked to independent schedules. Even though work activities from the two programs might coincidently occur within the same geographic location of the complex, schedules and objectives were never interconnected or related to the other program. Under this arrangement, the development of regulatory documents was usually duplicated as well as sampling activities at co-located facilities. Often previous contamination problems associated with former production facilities were related to environmental problems. Similarly, previous activities to remediate environmental contamination problems involved former production facilities. Therefore, there is a direct relationship between the two programs. It was commonplace to have the D\&D program sample the interior and residual materials of a former production facility and the soil and groundwater program sample soils and groundwater adjacent to the same facility and neither organization would facilitate communication with the other since each department had different objectives. This situation represented the loss of opportunity to optimize data collection and improve sampling efficiency, not to mention the loss of opportunity to resolve problems in a comprehensive manner.

The regulatory community would become concerned with this arrangement since duplicate sets of documents were being produced which would over-stress their limited personnel resources. Resolution of sometimes serious problems would often need to be postponed or delayed because the schedules and budgetary requirements for the programs were not coordinated. As an example, situations would arise where a major closed nuclear production facility would be left out of a comprehensive plan to address soil and groundwater contamination within the common boundary of a production area. It was just as likely for major production facilities within a common production area to be decommissioned and not address soil and groundwater contamination beneath and adjacent to the facility. Under the old paradigm, each former production facility and each waste site was regarded as a separate and independent entity requiring its own set of regulatory documents, budgets, schedules, and staffing resources. This was not a resource efficient path. 


\section{THE NEW PARADIGM}

Soon, it became apparent that the two programs were dynamically linked; one responsible for the source of contamination (former production facilities) and the area external and adjacent to the facility as the target for soil and groundwater clean up. Conceptually, the activities for both programs needed to be considered as one activity which required the two programs to be combined in a single integrated new program which would use a systematic approach to completing a comprehensive, area-wide closure by integrating DDP and SGP program scope.

It was critical to integrate the DDP and SGP to coordinate their schedules, budgets, and regulatory commitments which required a new framework for how work was completed to optimize the available resources.

One of the pieces of the new framework was to no longer treat independent waste sites and former production facilities as individual entities under the regulatory umbrella. A new strategy was conceived to remediate soil and groundwater waste sites together with former production facilities to be decommissioned and deactivated. This was a logical association since discrete production processes were co-located with waste sites within well defined geographical areas. For example, nuclear reactors were located within specific, special purpose geographical areas along with all of their supporting facilities. Within these geographical areas were multiple discrete waste sites containing soil and groundwater contamination sourced from the operation of the facilities and waste disposal methods over a period of 50 years as illustrated in Figure 1.

This was the central theme for the integration of the two programs. Not only could the former production facilities be decommissioned and deactivated but the resultant soil and groundwater contamination from those facilities could be concurrently investigated and remediated.

With this area wide approach the SRS could address multiple groups of waste units simultaneously with large groups of facilities within the same geographic area. By dealing with the geographic area comprehensively allowed several other benefits.

The area end state could be determined much more easily since all environmental media contamination and contaminated facilities were being addressed simultaneously. This allows a longer and more comprehensive planning to determine future uses for the land involved in the projects. As an example at SRS, a former reactor and its support facilities might be decommissioned and deactivated in-situ. The reactor vessel itself could be entombed inside a reactor building after adequate engineering controls have been constructed. This would be followed by long-term environmental monitoring and future stewardship of the area to maintain institutional and administrative control over the area for protection of the environment and human health.

Another advantage of integration was to allow economies of scale to be applied for sampling designs for various environmental media including the D\&D facilities. Sampling within the area is economized because waste site boundaries overlap with buildings and with other waste sites. This allows the sampling to be optimized and reduces duplicative efforts. In turn, this allows remediation technologies to be applied on the appropriate scale to resolve comprehensive environmental problems and regulatory documentation can be combined into one set of documents opposed to multiple sets of regulatory documents. Formerly all waste sites and buildings would have required their own set of regulatory documents. Under the current approach only one set of documents needs to be developed for all the units within an area.

Figure 2 illustrates the dramatic reduction in the number of Federal Facility Agreement clean up milestones as a direct result of the integration of the soil and groundwater clean up with decommissioning and deactivation program activities. 


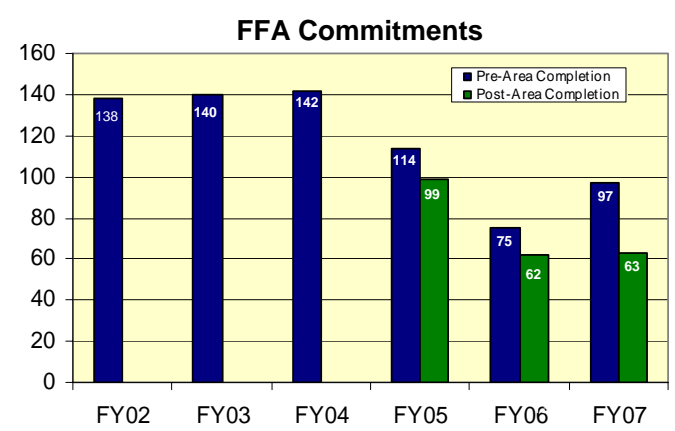

Figure 2. Illustration of the Reduction of Federal Facility (Regulatory Documents) Commitments as a Result of the Area Closure Process.

\section{EXAMPLES OF SUCCESSFULLY INTEGRATED EFFORTS OF A DECOMMISSIONING AND DEACTIVATION PROGRAM WITH A SOIL AND GROUNDWATER PROGRAM}

There are a number of practical examples to indicate the effectiveness of the integrated SGP and D\&D programs. T-Area was a process development and process testing area constructed in 1950 and was the first area selected for area closure under the integrated programs. The T-Area Closure Project included the combination of 5 waste sites plus 28 D\&D facilities. The area was turned over to the integrated programs (SGP and DDP) on September 30, 2004. The project was completed in two years which was four years ahead of the previously established schedule and resulted in the remediation of all the waste sites and the demolition of all 28 process facilities which included approximately $15,514 \mathrm{~m}^{2}$ of building floor area. Final remedial actions occurred in 2006 with the construction of a 10 -acre geo-textile low permeability, soil cover system over the area and the start up operations for soil remediation which includes a soil vapor extraction system. Figure 3 displays the before and after photographs. The area is now in an end state where risk to human health and ecological receptors and the future risk of migration of contaminants to the groundwater have been protectively managed.

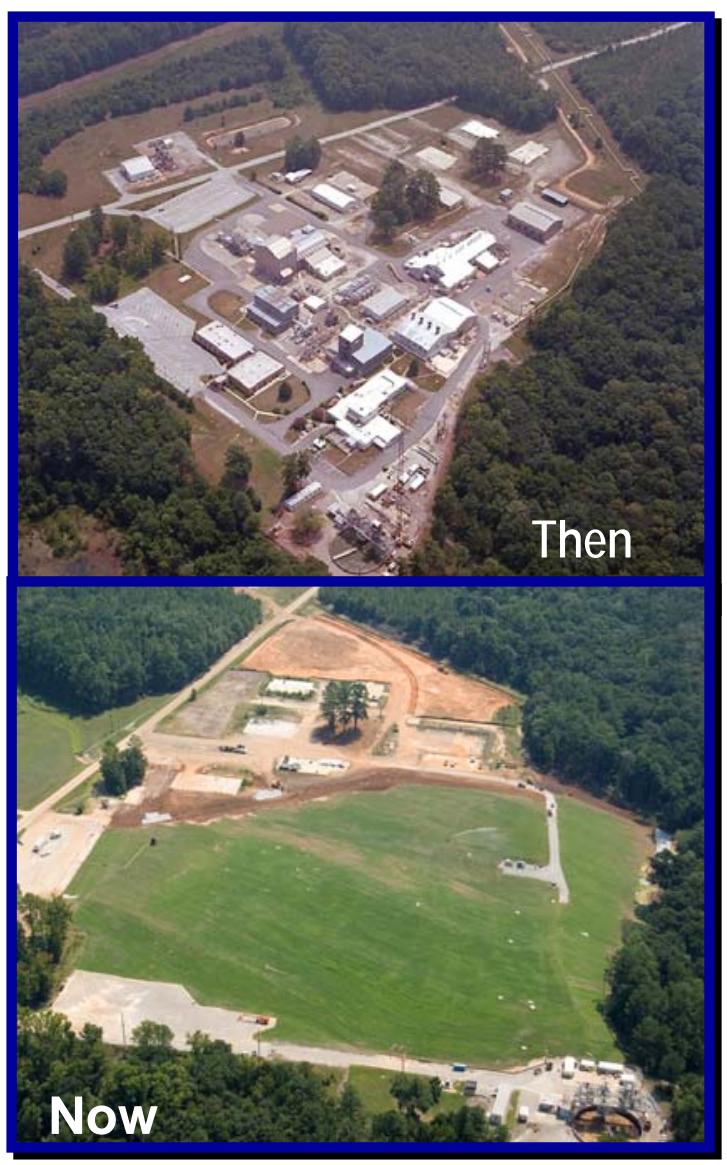

Figure 3. T-Area Before and After the Integrated soil and groundwater and decommissioning and deactivation program was implemented.

M-Area was a former nuclear reactor fuel and target manufacturing complex with support facilities. The M-Area Closure Project included 5 waste units and 48 D\&D buildings with a total of approximately $34,095 \mathrm{~m}^{2}$ of floor area. The M-Area project began in 2005 and final remedial construction activity will end in 2011 . At MArea contaminated soils were excavated to accelerate cleanup and achieve the final remedial goals. Additionally several innovative vadose zone clean up technologies are being used to remove solvent contamination which included dynamic underground stripping (DUS), soil fracturing, and injection of edible oils. Due to the severe groundwater contamination within this area (over 450,000 kilograms of solvents released) groundwater clean up activities will be continuing far into the future within this area. All 48 D\&D facilities have 
been demolished and removed from M-Area as shown in Figure 4. The area will be covered with a low permeability geotextilesoil cover system. Since soil contaminants and groundwater contaminants will remain in the future the end state will be restricted to limited industrial use.

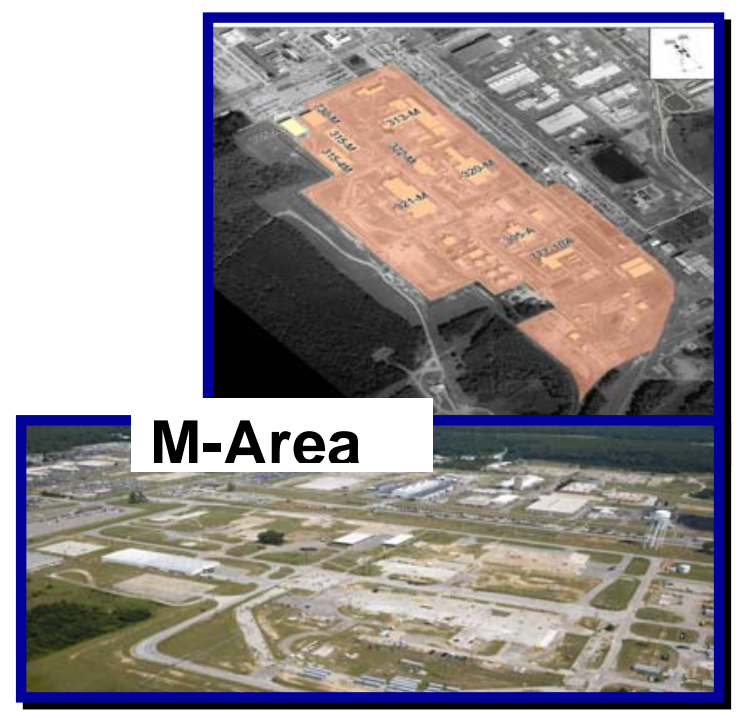

Figure 4. M-Area showing the locations of major production facilities before the Area Closure Project and after the project showing the remaining building slabs.

P-Area is a 2 square kilometer area for the operation of one of the SRS nuclear reactors and its support facilities. The reactor building is a large hardened concrete structure which contains assembly, process, disassembly and purification areas. All fuel and target assemblies have been removed and the reactor has been in shut-down mode since the 1991 . The reactor building itself has approximately $46,672 \mathrm{~m}^{2}$ of floor area and contains over $315,253 \mathrm{~m}^{3}$ of volume. The building contains 660 kilometers of wire, 15,081 metric tons of reinforcing steel and over 3 miles of process sewers with low level radioactive contamination. In addition, to the reactor building, P-Area also contained support facilities for the reactor including maintenance shops, water purification and treatment facilities, electrical substations, and administrative buildings. In all P-Area contains the reactor building, 22 D\&D buildings, 5 soil and groundwater waste sites, and 5 other potential soil and groundwater contamination source areas.

The soil and groundwater and decommissioning and deactivation programs have been integrated from the beginning of the P-Area Operable Unit which includes all the above facilities. This area represents the greatest challenge to both of the programs due to the size and nature of the activities that were conducted here. Negotiations and work is still continuing within the area.

Thus far progress has been exceptional with initially favorable negotiations with the stakeholders to consider an in-situ end state for the reactor building. This means entombment of the reactor vessel and its component equipment in place. In-situ end state discussions are continuing. All the soil and groundwater units have been investigated and approximately 18 of the support facilities have been removed. Negotiations on the details of the final remedial actions for the reactor building and waste sites remain to be finalized. It is anticipated that the substructure of the reactor building will be filled with a grout media and a type of low permeability cover system will be installed over the bulk of the process sewer system and will include biobarriers and reducing the overall height of the structure. Soil and groundwater waste sites will be remediated with a combination of soil vapor extraction, soil contaminant oxidation, and excavation. Any incidental waste generated at the soil and groundwater units may potentially be consolidated and disposed within the reactor building or under the low permeability cover system.

The final remedial actions are expected to commence in 2010 under the current schedule. If the two programs are successful this will represent the first final closure of a reactor area within the DOE complex. Basic challenges to complete the project will be securing the necessary funding for completion of the construction and effective negotiations with the regulatory community and the public for this approach. Public involvement has been solicited as the result of community meetings where anticipated plans have been discussed in an open forum. 


\section{CONSLUSIONS}

The integration of the D\&D and Soil and Groundwater Programs has had positive impacts on both the budget and schedule. The integration has resulted in cost savings by eliminating duplicative efforts in sampling design, data management, and in reducing the amount of regulatory documents that need to be generated. Because of economies of scale, sampling could be optimized within both programs and regulatory documents could be combined into a single set instead of multiple sets.

Because the objectives of each program were synchronized, an entire area could be comprehensively investigated and remediated to eliminate any residual risk. Because areas were being dealt with on a comprehensive basis, remedial actions could be dovetailed to meet the requirement of each of the programs. This has also resulted in economies of scale in that the remedial actions could also be integrated to address both the D\&D facilities and the soil and groundwater problems, saving significant time and money.

Finally, by comprehensively addressing all the environmental problems within an area simultaneously, it is possible to arrive at the end state for the area more easily than on a case by case, unit by unit basis. This has avoided numerous iterations of negotiations, documents, and work caused by dealing with each program separately and has resulted in greater overall efficiency. 